\title{
A Comparative Study on the Development of Teachers' Teaching in Sino-U.S. University
}

\author{
Chen Jia \\ Nantong University, Jiangsu, China \\ Shi Xiaoling \\ Second Affiliated Primary School of Jiangsu Nantong Normal School, Jiangsu, China
}

\begin{abstract}
The research on the development of teachers' teaching can make a comparative analysis between Chinese and American university, and then, put forward reasonable proposals for the development of teachers in Chinese university. This paper analysizes the development in practice teachers' teaching of Sino-United States (U.S.) university, combining the advantages of American faculty teaching development. For the development of Chinese college teachers' teaching, it puts forward some corresponding suggestions, hoping to further promote the development of teachers' teaching level, gradually strengthening the effect of personnel training in universities.
\end{abstract}

Keywords: comparison between China and the United States (U.S.), colleges and universities, the development of teachers' teaching

\section{Introduction}

As China attaches great importance to the popularization of higher education, higher education and teaching work has made certain achievements. However, it also faces corresponding problems: The improvement of teaching quality, the reform, and innovation of personnel training are facing severe challenges. Therefore, it is necessary to draw on the experience of advanced education in the developed countries, conduct the research to the development of teachers' teaching in Chinese university, and clearly survey the teaching development problems in China. We should reform, innovate, and gradually improve the teaching effect, so as to provide high-quality education guidance services for students.

\section{A Comparison of Teaching Practice Between Chinese and American College Teachers}

\section{The Teaching Practice of College Teachers in the United States (U.S.)}

In the process of long-term participation in educational reform and practical exploration, American university teachers have made some achievements in education. They reflect the advantages of educational practice in many ways, which has certain reference significance for the development of teachers in Chinese university. The successful experience of teachers' teaching in American university practice to refine the interpretation that advanced place teachers' development mainly from following aspects:

1. The teachers' teaching development in mechanism construction is improved;

Chen Jia, B.A., assistant researcher, College of Physical Science, Nantong University.

Shi Xiaoling, B.A., the senior, Second Affiliated Primary School of Jiangsu Nantong Normal School. 
2. The teaching content development is targeted, rich, and comprehensive;

3. The teaching mode of development is flexible;

4. The combination of teachers' individual development and overall development;

5. Through development of teachers, teaching of objectivity, teachers' teaching, and students' learning to improve the development of the interaction of reflected.

The construction of teachers' teaching development mechanism is analyzed from the category view and the development of teaching institutions teachers' colleges and universities in the U.S. has basically realized the organification. Whether in school or in the community, it has established the teaching and development of specialized agencies to provide support for teachers' development. For example, University of Maryland has set up special leaders in different departments to manage teachers' teaching development, effectively supporting the steady development of teachers' teaching development (Zeng, 2015).

Analysis from the type of the institution perspective, university teachers' teaching development organization in the U.S. has diverse characteristics, such as office organization, institution, society project organization, institutions, and fund center institutions. School of the Varavara Community Center, New York University Teaching Excellence of Teacher Professional Development Committee is one of the typical and capable of supporting the development of teachers' teaching from various aspects. But, if we analysis from the teaching mode of development flexibility perspective, we could find that American college teachers' teaching development shows the flexibility and diversification of the U.S.. It also provides the measures of development workshops, teaching training, counseling, and teaching motivation diversification for teachers' teaching development. Even, it organizes a luncheon and teaching special anniversary dinner of the teachers' teaching activities to meet the diverse needs of teachers and the effective protection of the actual effect of teachers' development. The advantages of American teaching development reflected in the multi-angle. During the process of reform and innovation on the development of college teachers' teaching, we should actively learn from the successful experience of the U.S., create a good condition for the development of teachers' teaching, and enhance the actual effect of the development of teachers' teaching in university.

\section{Teaching Practice of College Teachers in China}

In the process of the development of Chinese higher education, we made a study of the development of university teachers' teaching. We also try to construct various types of Teacher Education Development Center and actively organize teachers' training institutions, teaching reform activities and academic exchange activities, the institutions, and personnel arrangement and we have achieved initial the results. By means of the training works, they also effectively improve the teaching level of development, which has an important effect on comprehensively promoting Chinese higher education (Xiong, 2013). However, it is undeniable that the development of teachers' teaching in Chinese university has been continuously trying and exploring, it has achieved remarkable results, and the construction of teaching development centers and training centers, which is attracting more and more attention. However, due to the time of development is relatively short and the theory is not perfect, there are still some problems after these achievements, which caused a serious impediment to the development of teachers' teaching in Chinese college. Thus, the teachers' teaching is not conducive to the development and raises the level of internationalization of higher education development.

Through detailed interpreting the existing problems in the development of teachers' teaching in Chinese college, we find that the problem is embodied in the following aspects: 
1. There is deviation in the cognition of some colleges and universities and teachers have the wrong orientation of the development of teachers' teaching. Teachers' teaching development can only borrow to help train means to improve teaching skills, but cannot guarantee to deepen the all-round development of teachers and thoughts, so some of universities do not agree to participate in the activities of teachers' training and teaching development.

2. The system construction of the development of Chinese teaching is still not perfect without setting up a special training system of university teachers. Teaching evaluation system development of university teachers is not enough. There have been some problems, such as not achieving effective incentive for teachers and lack of enthusiasm to participate in the development of college teachers' teaching training in the application of teaching evaluation incentive mechanism development. It will also have adverse effects on the development of the corresponding teaching (Xie \& Guan, 2013).

3. The teachers in development of practical teaching activities lack of rationality and part of the concept of teaching development work settings is not clear enough, so the choice of the content is not specific and comprehensive. Also, the teaching mode of development do not focus on the innovation, which cause part of the development of teaching activities become a mere formality, greatly limits the optimization, and innovation of college teachers' teaching development in China. In a nutshell, current development of Chinese college teachers' teaching is still in the early stages of development and the construction is still not perfect.

No matter how to explore the construction of training institutions, there are some problems in the system settings or practice. We need to explore and practice in the next period and learn from the advanced experience of western developed countries. To fully implement and gradually promote the development work of teachers' teaching, the reform and innovation of the development of teachers' teaching in China should be done.

\section{The Enlightenment of Teaching Development Comparison Between Chinese and American Colleges and Universities}

In the comparative study of the development of teachers' teaching in Sino-U.S. university, we can form a comprehensive understanding on the advanced development of teachers' teaching and development deficiencies in American universities. Chinese university teachers' teaching can contact the basic situation of China, draw lessons from the advanced experience of the U.S., and reform and innovate the teaching work for the development of high school teachers. It can create better the development of teachers' teaching conditions and boost the level of higher education, the continuous improvement.

\section{Promoting Organic Coordination Among Departments}

The development of teachers' teaching involves multiple departments. To ensure the steady progress of teaching development, we should build a perfect supporting system, which requires the organic and coordinating development of teachers' teaching institutions. Then, we should make teaching development activities organic, optimize universities, and comprehensively promote the teachers' education development work (Wu, \& Zhou, 2015). In practice, the university should try to learn from the successful experience of the U.S.. We should combine with the actual situation of school choice mechanism type teaching development to establish the teachers' development center in schools. It can play a leading role in the school teaching development and further promote the development of teachers' teaching work in many departments. The multi-section coordination advantage, synergy formation, and development of teaching can ensure the 
comprehensive implementation of teachers' development. Under the active organization and coordination of various departments, we believe that the development of university teachers' teaching in China can be supported by the functions of various departments and achieve the desired development results, so as to provide effective support for the steady development of educational reform in colleges and universities.

\section{Giving More Autonomy to Schools}

There is a close relationship between the development of teachers' teaching and the management of colleges and universities. Only by fully supporting the development of teachers' teaching in colleges and universities, can we steadily promote the development of teachers' teaching and achieve remarkable results, (Wu, 2014). Therefore, we should correctly understand the importance of university teachers' teaching as the main carrier and the development of basic units, and carry out more autonomy and teachers in the organic and practical activities. Striving to be able to play an active role in the development of teachers' teaching, arranging flexible work and unified management to achieve the development of teachers' teaching work can further to improve the actual effect of teachers' development. In the process of the specific organization and carrying out teaching development work, the administrative department of education in colleges and universities should give some support to independent colleges and universities implement teaching development, development and undertake related projects. It promotes the universities to actively participate in teaching development work and further development in improving the work effect. At the same time, it ensures the college of education.

\section{Full Play to Teachers' Subjective Initiative}

In the development of teachers' teaching work, teachers in colleges and universities are the subject of direct participation. Also, they can enjoy the development of teachers' teaching achievements and they have the crucial influence the development of subjective initiative. Therefore, subjective desire and the teacher's participation should be in the development of teachers' teaching on teaching effectiveness. The new period, to gradually improve the basic situation of college teachers' teaching and the development of China, to ensure that teachers' teaching development can achieve more significant results, you should pay attention to teachers' subjective initiative. Also, you should let the teachers have a correct understanding of the development of teaching and notice the urgency and importance of active participation in teaching improvement, so as to raise teacher's consciousness of active participation (Zhou, 2014). Based on this, the university should set up the corresponding organization activities and build a sound incentive mechanism to arouse students' intrinsic motivation of self-development. In the school organization and planning, students should actively participate in the development of teaching activities to adapt external development, explore the potential individual excitation, and achieve better teaching development and contribution the power for college education.

\section{The Effective Improvement of the Organization Frame Structure}

The improvement of the organizational framework is the guarantee for the effective operation of teachers' teaching development. So, in the process of teaching reform and innovation of the development work of university, teachers in China should pay attention to improve the organizational framework, combined with the goal and the basic orientation of teachers' development, and completed the design of the organizational structure. The organizational framework will check and balance into a unified system, realize the dynamic unification of three aspects and ensure all the authority showing the development status of the specific and formal (Huo, 2016). On this basis, the use of resources should also be mutual exchanges and development of 
teachers' organizational framework to improve effective organization of teachers' contribution. You can gradually improve the basic status of university teachers' teaching the development of China, achieve the development of teachers' working effect ideal, and build a real change combined with external changes and strategic objectives of the organization framework dynamic adjustment.

\section{Exploring the Multi-Level Development Model}

The development of teaching work in colleges and universities to meet the college teachers' needs from different levels should pay attention to introducing the hierarchical idea. It provides teaching service for college teachers' development, recognition, and affirmation in the reform and innovation of development mode. It also is trying to build a multi-level development model, to provide some support and guarantee the step by step for different levels of teachers' development, and to have teachers participated in teaching activities of development. As for the different ages of teachers, teachers should develop differentiated development plan, which can make up the shortage for teachers' education skills and occupation burnout situation for teachers. To provide targeted services and ensure the effect of teachers' development, we should provide a good support to promote the development of the modernization of teaching.

\section{Building a Scientific Evaluation System}

In the process of comprehensive reform and innovative teaching, to ensure the development of teachers' teaching is always in the right direction, we should also pay attention to the different stage of teachers' development work summary and evaluation, determine the deficiencies and the existence of a fruitful teacher at this period, and form an objective understanding of the periodic development of teaching (Liu, 2016). Based on this, constructing a comparatively scientific evaluation system, have an positive effect on the development of teachers' teaching in school education and have the evaluation index as teachers and students' participation in the project, and form a new understanding of the teaching development work's advantages and disadvantages. Under the guidance of teaching development, teachers in colleges and universities develop steadily, which provide good support for the development of teachers in colleges and universities.

\section{Conclusion}

To sum up, according to the comparative study on the development of college teachers' teaching, we summarize the shortcomings of the current development of teachers' teaching in Chinese college and put forward reasonable suggestions combined with the advanced experience of American teaching. It can promote the development of college teachers' teaching level to further improve the teaching ability of the teachers. Accordingly, it produces the crucial influence on teachers' personal development and Chinese higher education internationalization. Therefore, it is of practical significance to take the comparative study of the teaching development of Chinese and American colleges and universities as the research object, which is worthy of further exploration.

\section{References}

Huo, Y. (2016). A comparative study of teachers' teaching evaluation in Chinese and American colleges and universities. Shanxi, China: Shanxi Normal University.

Liu, Y. (2016). A comparative study of university teachers' development institutions in China and the United States. Hunan, China: Hunan Agricultural University.

$\mathrm{Wu}$, Y. J. (2014). A comparative study on the development of young teachers in colleges and universities in China and the United States. Jiangsu, China: Nanjing Normal University. 
Wu, G., \& Zhou, J. R. (2015). Comparison and enlightenment of teaching evaluation between Chinese and American universities: Based on a comparative study of two schools. Education Evaluation Research in Shanghai, 3, 22-28.

Xie, M. R., \& Guan, L. (2013). Comparative study of teachers' training in Chinese and American colleges and universities. Adult Education, 10, 126-128.

Xiong, J. J. (2013). Comparative study of teachers' development in Chinese and American colleges and universities. Development and Evaluation of Higher Education, 29(5), 76-81.

Zeng, Y. (2015). Comparative study on the teaching development of university teachers in China and the United States. Hunan, China: Hunan University.

Zhou, J. R. (2014). Comparative study of college teachers' teaching evaluation: Taking Shanghai Normal University and California State University Northridge for example. Shanghai, China: Shanghai Normal University. 